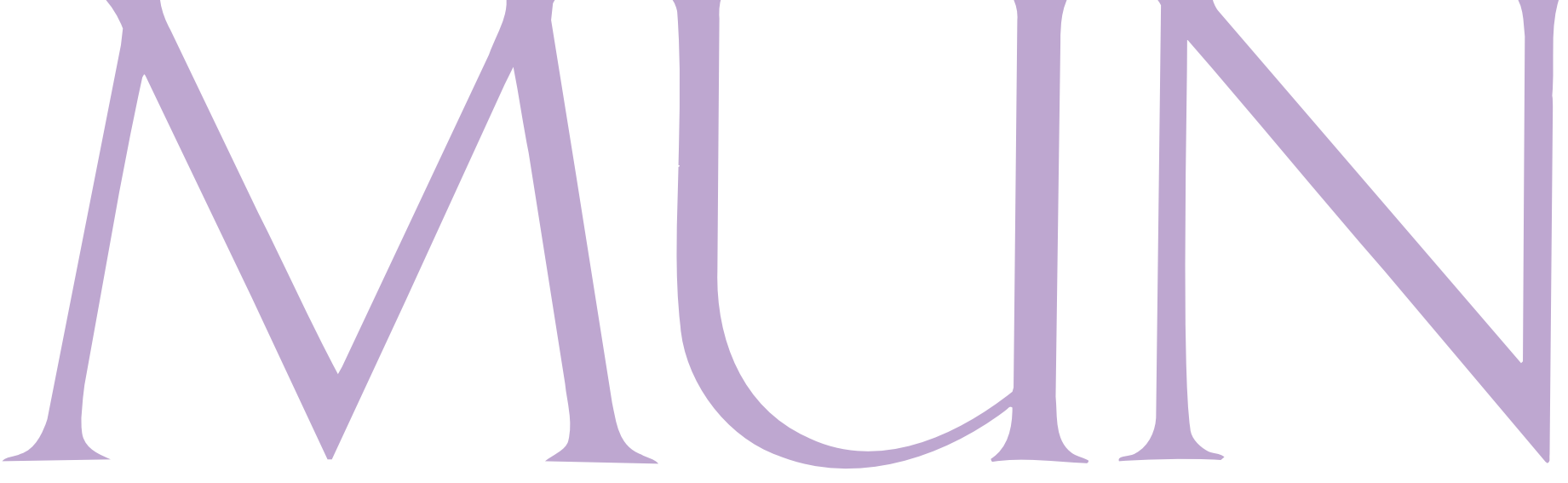

Meio ambiente

\section{Fé na ciência para salvar a Amazônia}

Nem sempre aliadas e, não raro, inimigas declaradas, ciência e religião deram as mãos no Sínodo dos Bispos para a Região da Pan-Amazônia, reunião de líderes católicos ocorrida em outubro passado, no Vaticano, para discutir respostas da Igreja Católica a questões ligadas ao meio ambiente e aos povos indígenas.

Sínodos são uma espécie de consulta do papa a especialistas. $\mathrm{O}$ documento resultante da reunião, a exortação apostólica, é elaborado após os convocados debaterem as questóes em pauta para que, posteriormente, o papa oriente o clero ao redor do mundo sobre como agir. No Sínodo da Amazônia, as diretrizes foram "aumentara presença da igreja na região", "reforçar a defesa da ecologia, defender a demarcação de terras indígenas", "rejeitar empreendimentos com impactos negativos para os povos" e "incentivar uma maior participação nas discussões políticas relacionadas", entre outras. De acordo com um dos responsáveis pela sua elaboração, o cardeal Pedro Barreto Jimeno, do Peru, "tudo fortemente pautado por evidências científicas".

O texto classifica a Amazônia como "coração biológico" ameaçado. "A ciência está nos mostrando que esse coração está doente e os cientistas não estão errados. Dois e dois são quatro em qualquer parte

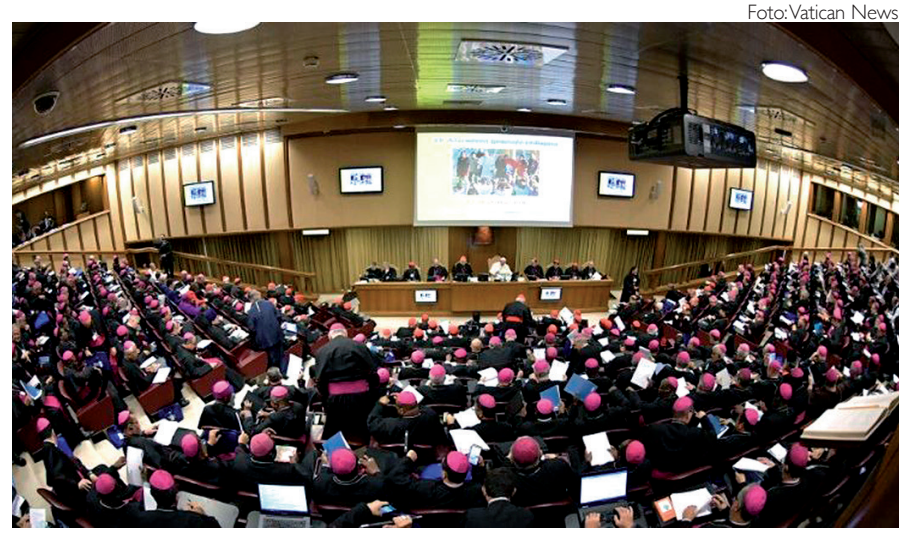

Igreja também busca respostas a questões ligadas ao meio ambiente

do mundo", defende o cardeal, um dos três prelados escolhidos pelo Papa Francisco para supervisionar a organização do evento. "Não podemos combater adequadamente essa degradação ecológica se não prestarmos atenção às causas diretamente relacionadas a ela, que são humanas - e a ciência nos tem fornecido uma importante bússola para isso."

Dessa forma, referências bíblicas compartilham espaço na exortação apostólica com citaçôes da Academia Nacional de Ciências dos Estados Unidos: “40\% de desmatamento constitui um ponto de inflexão do bioma amazônico rumo à desertificação, o que significa a transição para uma nova condição biológica geralmente irreversível", alerta o documento.

SEM CETICISMO Para a jornalista ambiental Nádia Pontes, que cobriu o sínodo para a empresa pública de radiodifusão alemã Deutsche Welle, a igreja não tem dúvida da influência humana na transformação do meio ambiente. "As mudanças climáticas e sua relação com a atividade humana foram tratadas na ocasião como uma realidade, assim como o papel da Amazônia para o planeta, e a igreja parece não querer se furtar da importância de sua presença na região na busca por soluções", conta.

Uma das iniciativas nessa direção é o alerta que o documento faz sobre a região não ser uma fonte inesgotável de recursos, "buscando-se por um novo paradigma de desenvolvimento sustentável, no qual urgências comerciais não se sobreponham à conservação do meio ambiente e aos direitos humanos".

As bases para esse novo paradigma foram fornecidas por cientistas - entre eles, o climatologista brasileiro Carlos Nobre, responsável pela apresentação do conceito de bioeconomia na abertura do sínodo, no Vaticano. Nobre integra o Painel Intergovernamental de Mudanças do Clima (IPCC), ganhador do Nobel da Paz de 2007. A defesa do cientista é por uma "quarta revolução industrial" iniciada pela bioeconomia, baseada no aprofundamento do conhecimento da biodi- 

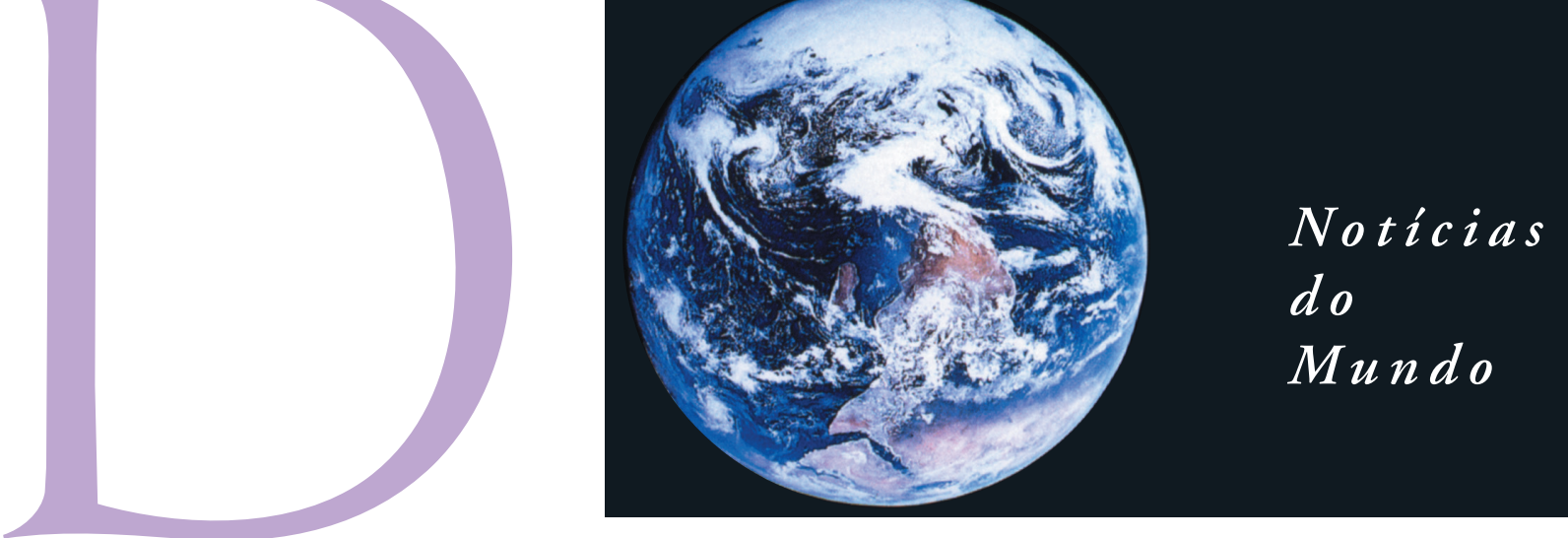

versidade local para que seus potenciais sejam plenamente aproveitados por uma economia que mantenha a floresta de pé. "São muitos os segredos guardados pelas plantas da Amazônia, como princípios ativos para novos medicamentos, óleos e essências, uma diversidade incalculável de matéria-prima para tecnologias do futuro e tudo aquilo sobre o que ainda não se sabe. Derrubar a floresta para convertê-la em pasto é prescindir desse imenso potencial tecnológico para as próximas décadas e gerações", alerta.

No Instrumentum Laboris, documento católico que serviu de base para as discussões do sínodo, o Vaticano diz que “a vida na Amazônia está ameaçada pela destruição e exploração ambiental e pela violação sistemática dos direitos humanos elementares da população amazônica", e que "a ameaça à vida deriva de interesses econômicos e políticos dos setores dominantes", denunciando o papel das empresas extrativistas no processo.

MAPA CIENTíFICO A conversão da mata em nada é uma realidade para as florestas tropicais ao redor do mundo: menos de $50 \%$ de todas que já existiram permanecem de pé, com grande parte da cobertura florestal remanescente afetada pela extração madeireira e por incêndios, mineração e caça. Um estudo da Escola Superior de Agricultura Luiz de Queiroz da Universidade de São Paulo (Esalq-USP), com a colaboração de pesquisadores de instituições da Alemanha, da Austrália e dosEstados Unidos, oferece um caminho para a bioeconomia. Foram identificadas nele oportunidades de restauração em paisagens de floresta tropical de diversas regiōes do planeta, considerando a viabilidade socioambiental de cada uma.

Após quatro anos deanálises deimagens de satélites cruzadas com dados socioeconômicos das regiôes incluídas no estudo, os pesquisadores cobriram um conjunto de dados espaciais em escala global. "A ideia é que esses dados ajudem a atingir benefícios socioambientais, com consequências diretas e indiretas para a natureza, as economias e o bem-estar humano", conta o engenheiro-agrônomo Pedro Brancalion, do Departamento de Ciências Florestais da Esalq. Os dados foram publicados em 2019, na Science Advances e apontam que a área global restaurável em paisagens tropicais é de 863 milhões de hectares (Mha), um território maior que o do Brasil. Para Carlos Nobre, esse é apenas um dos caminhos que a ciência oferece. "É preciso ouvir nossos cientistas, tão sensíveis e dedicados à Amazônia, assim como os povos que a habitam desde os tempos ancestrais."

\section{PROTAGONISMO IN-} dígena Por conta do que apontam os cientistas sobre a gravidade do desmatamento e da influência humana nas mudanças climáticas, entre outros perigos para a floresta, o Sínodo da Amazônia recebeu fortes críticas do governo brasileiro. Outra questão à qual a igreja se dedicou também diz respeito à postura do Estado na região, apontou o bispo emérito do Xingu, Dom Erwin Kräutler, em entrevista à jornalista Nádia Pontes.

De acordo com ele, "o Sínodo da Amazônia colocou indígenas no centro da atenção e a Igreja Católica vai exigir que o governo brasileiro os proteja”. Para o clérigo, a razão do descaso com a região e seus povos é financeira. "O presidente coloca na cabeça que temos que abrir a
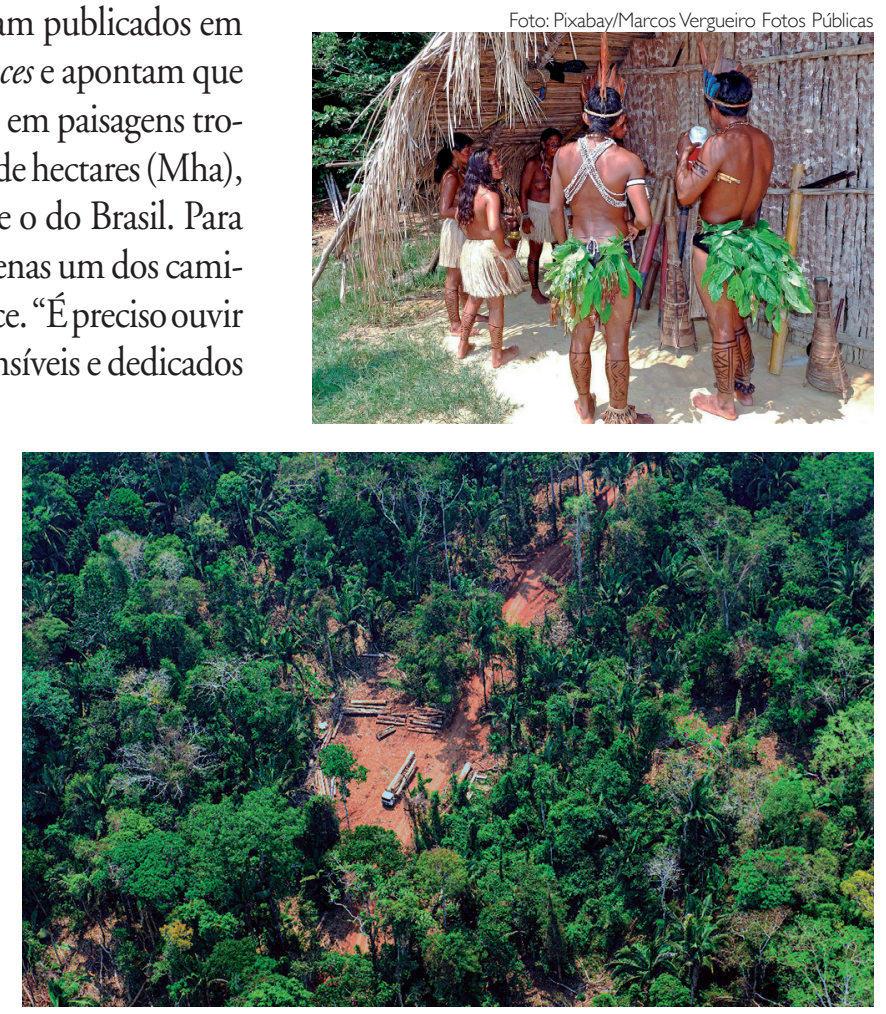

Defesa dos povos indígenas foi uma das diretrizes do Sínodo 
